\title{
MATEMÁTICA PARA A CIDADANIA: DISCURSOS CURRICULARES SOBRE EDUCAÇÃO MATEMÁTICA PARA SURDOS
}

\author{
Bruna Fagundes Antunes Alberton ${ }^{1}$
}

Adriana da Silva Thoma ${ }^{2}$

\begin{abstract}
Resumo
Neste artigo analisamos os discursos sobre Educação Matemática e como eles constituem as práticas desenvolvidas com alunos surdos. Como material de análise consideramos os Parâmetros Curriculares Nacionais (PCN) da área de Matemática para o Ensino Fundamental e os Projetos Político-Pedagógicos (PPPs) de três escolas para surdos. As análises são feitas a partir da noção de discurso desenvolvida por Michel Foucault (1996). Também dialogamos com Viana e Barreto (2014) e Borges e Nogueira (2013) para pensar sobre Educação Matemática, bem como com Hall (2000), Thoma e Klein (2010) e Thoma (2012) para discutir sobre identidades, diferença surda, currículo, cultura e poder. Nos PCN e PPPs analisados, é bastante presente o discurso de que sujeito surdo precisa construir conhecimentos matemáticos para se constituir um cidadão participativo, crítico, justo e autônomo. Assim, nosso recorte aqui, são os discursos sobre Matemática para a Cidadania.
\end{abstract}

\footnotetext{
${ }^{1}$ Possui graduação em Matemática pela Universidade Luterana do Brasil (2010) e em Letras/Libras pela Universidade Federal Santa Catarina (2011) - polo Universidade Federal de Santa Maria (UFSM). Mestre em Educação pela Universidade Federal do Rio Grande do Sul (UFRGS), na linha de Estudos Culturais em Educação, sob orientação da profa. Dra. Adriana Thoma, com Bolsa do CNPQ (Conselho Nacional de Desenvolvimento Científico e Tecnológico). Certificada pelo Exame Nacional de Proficiência (PROLIBRAS) no Uso e no Ensino da LIBRAS - Nível Médio e Nível. Atualmente é professora Assistente I da Universidade Federal do Rio Grande do Sul, atuando no Departamento de Estudos Especializados da Faculdade de Educação (DEE/FACED). Coordenadora voluntária do Fórum de Estudos Surdos na área de Matemática, Física e Química (FESAMFQ). Endereço: Rua Panamaricana, 150/apto 301 - Bairro Jardim Lindóia - Porto Alegre/RS, Brasil. CEP: 91050-000. Endereço eletrônico: brunafantunes@gmail.com

${ }^{2}$ Possui graduação em Educação Especial pela Universidade Federal de Santa Maria (1994), mestrado (1997) e doutorado em Educação (2002) pela Universidade Federal do Rio Grande do Sul. Atualmente é professora Adjunto IV da Universidade Federal do Rio Grande do Sul, atuando no Departamento de Estudos Especializados da Faculdade de Educação (DEE/FACED) e no Programa de Pós Graduação em Educação (PPGEDU). Coordenadora do Grupo de Pesquisas SINAIS: Sujeitos, Inclusão, Narrativas, Identidades e Subjetividades. Integrante do Núcleo de Estudos sobre Currículo, Cultura e Sociedade (NECCSO/UFRGS) e do Grupo Interinstitucional de Pesquisa em Educação de Surdos (GIPES). Endereço: Rua Santa Rita, 53/apto 407 - Bairro Floresta - Porto Alegre/RS. CEP: 90220-220. Brasil. Endereço eletrônico: asthoma@ terra.com.br
} 
Palavras-chave: Estudos Culturais; Educação Matemática para Surdos; Língua Brasileira de Sinais; Identidades Surdas; Discurso

\section{CONTEXTUALIZAÇÃO DA PESQUISA}

Quais os discursos curriculares sobre a Educação Matemática e como eles constituem as práticas desenvolvidas neste campo de conhecimento na educação de surdos? $?^{3}$. Nosso foco de investigação são os discursos curriculares sobre a Educação Matemática para surdos, através da análise dos Parâmetros Curriculares Nacionais (PCN) da área de Matemática para o Ensino Fundamental e dos Projetos Político-Pedagógico (PPPs) de três escolas para surdos. As escolas, nomeadas pelos símbolos matemáticos $\alpha$ (alfa), $\beta$ (beta) e $\gamma$ (gama), trabalham na perspectiva bilíngue para a educação dos alunos surdos.

Em articulação com os Estudos Surdos e Estudos Foucaultianos, olhamos para questões como cultura surda, identidades surdas e educação e a partir de tais articulações, "aproximamo-nos daqueles pensamentos que nos movem, colocam em xeque nossas verdades e nos auxiliam a encontrar caminhos para responder nossas interrogações." (MEYER; PARAÍSO, 2012, p. 17).

Pesquisas como a de Capovilla (2011) têm se ocupado em analisar as práticas que ocorrem em escolas de surdos, onde a língua de sinais e a cultura surda estão no centro das propostas pedagógicas e dos planejamentos. Em uma proposta bilíngue de educação, as questões da língua de sinais e do português escrito consideram os artefatos da cultura visual ${ }^{4} \mathrm{e}$ a forma como estes podem ser utilizados na sala de aula. Morais e Lunardi-Lazzarin (2009), no artigo Pedagogia e Diferença como currículo das escolas de surdos, colocam que: “localizar o currículo na 'Pedagogia da Diferença' é também uma forma de 'virada cultural e linguística': um olhar diferenciado diante dos discursos e das práticas que envolvem esse campo.” (2009, p. 21). Este olhar diferenciado sobre a cultura surda, com as experiências

\footnotetext{
${ }^{3}$ Interessadas em entender como vem ocorrendo a educação matemática em escolas de surdos, essa pergunta orientou a investigação de mestrado da primeira autora desse texto, sob a orientação da segunda (ALBERTON, $2015)^{3}$. Nesse artigo, apresentamos uma das unidades construídas nas análises.

${ }^{4} \mathrm{O}$ aspecto visual da aprendizagem dos surdos requer estratégias visuais, pois o sujeito surdo explora o mundo, faz suas indagações e encontra suas possíveis respostas pelo olhar.
} 
visuais inseridas no currículo, apresenta novas concepções culturais para o ensino de alunos surdos.

Para compreender os sujeitos de um discurso, na educação de surdos, é preciso pensar a Matemática sob o aspecto visual, conhecer o coletivo e a comunidade a qual este pertence. Analisar os discursos (clínico, psicológico, pedagógico e outros) e refletir sobre suas implicações na educação, talvez nos possibilite produzir novos discursos que atendam às diferenças surdas na educação. Na perspectiva de Michel Foucault (1996), o discurso produz e constitui os objetos e sujeitos de que tratam, construindo identidades. Para Veiga-Neto (2011), o discurso é visto como prática e movimento, produzido nas experiências de mundo. Nesse sentido, o discurso, produzido pela linguagem, constitui a experiência e orienta as práticas de se fazer educação.

Refletir sobre o currículo, por sua vez, mostra que, este, não é simplesmente uma seleção, organização e distribuição do conhecimento, mas serve para formar sujeitos de determinados tipos, de acordo com a lógica que se pretende. O que propõe o currículo visa sempre um determinado tipo de sujeito a ser constituído, conforme coloca Skliar sobre currículo e identidade é necessário "uma política de identidades surdas, em que questões ligadas à raça, à etnia, ao gênero e etc, sejam também entendidas como 'identidades surdas'; identidades que são, necessariamente, híbridas e estão em constante processo de transição" (2013, p. 28). A ausência de marcadores da cultura surda nos livros didáticos e recursos visuais disponíveis para a educação matemática fazem parte de um discurso educacional que precisa ser problematizado.

$\mathrm{Na}$ educação de surdos, o reconhecimento e valorização das diferentes formas de aprendizagens matemáticas talvez possam ajudar a desenvolver novas ações para ensinar e aprender. Os conhecimentos matemáticos precisam estar vinculados aos grupos, às diversidades culturais, às identidades, à política e ao poder, às diferenças de ser e de pensar o mundo e suas várias dimensões. Kátia Carneiro (2012) escreve sobre a importância de valorizar as experiências culturais e sociais do aluno surdo, para que ele vincule seus próprios conhecimentos com os conteúdos selecionados pelo currículo, tornando-o mais receptivo ao que vai ser trabalhado na escola.

O discurso curricular presente nos PCN e nos PPPs consideram diferentes culturas e, cada aluno surdo, como indivíduo de jeito e saber diferentes, sugerindo que cabe ao professor 
conhecer a cultura e a identidade de seus alunos antes de planejar suas aulas e suas estratégias 5 .

A cultura surda abrange a língua, as ideias, os costumes e os hábitos do povo surdo. É constituída por sujeitos surdos que se comunicam na representação visual dos fatos. Essa cultura tem procurado abrir, na sociedade, um espaço igualitário para o povo surdo, buscando o respeito e o fortalecimento de suas identidades. Assim, os indivíduos surdos constituem e produzem, a partir de suas vivências culturais, concretizando-se na experiência e na comunicação visual, imprimindo seu jeito de construir o mundo. A cultura surda tem como marca principal a língua de sinais, a língua que garante ao aluno surdo constituir-se como um sujeito de linguagem, interagindo com outros surdos, em uma comunidade surda.

Cada vez mais, faz-se necessário a escola estar atenta às mudanças que acontecem todo dia, às novas teorias e concepções que surgem, às mudanças de novos tempos. Mas, além disso, os professores que trabalham com os alunos surdos têm, na cultura surda e nas suas especificidades, desafios para desenvolver uma educação que instigue o aluno a pensar e resolver questões cotidianas. Ter conhecimento específico na área da educação para surdos; conhecer língua de sinais e suas especificidades linguísticas e culturais; entender as múltiplas identidades surdas e ser fluente em Libras, constitui base sólida para o ensino de estudantes surdos. Juntamente com as questões de formação do professor de alunos surdos, também proporcionar aos alunos a convivência com seus pares, possibilita o exercício da língua, segundo Thoma (2012), a "importância de alunos surdos serem educados em espaços escolares onde haja outros surdos" é defendida porque auxilia o processo de aquisição da língua, do conhecimento e da identidade. Na troca de experiências entre surdos, surgem novas possibilidades de exploração de outros mecanismos de aprendizagens. Surdos que vêm de diferentes culturas, que apresentam diferentes identidades, se beneficiam dessa troca de experiências, agregando novas possibilidades de aprendizagem para o grupo.

As questões culturais também são importantes para a construção de conhecimentos matemáticos. Desenvolver um currículo que proponha um estudo sobre cultura e identidade do grupo a que se destina é proteger e valorizar as marcas de identidade desse grupo. Um olhar mais detalhado sobre o currículo e a educação matemática para surdos implica em trazer a cultura e identidade para dentro dos planejamentos: a cultura visual, a necessidade de recursos e materiais específicos são questões importantes para pautar as discussões

\footnotetext{
${ }^{5}$ Sobre planejamento e estratégias de ensino de matemática para surdos, ver Borges e Nogueira (2013), Arnoldo Jr, Ramos e Thoma (2013) eViana e Barreto (2014).
} 
pedagógicas, filosóficas, didáticas e metodológicas para alcançar os objetivos propostos para esta educação. Pensar como essas práticas produzem resultados em uma proposta bilíngue, analisando o currículo e as identidades envolvidas, contribui com a organização e planejamento de ações pedagógicas. Essas práticas, muitas vezes ignoradas, resultam em currículos desarticulados das diferenças visuais dos surdos, como colocam as autoras Morais e Lunardi-Lazzarin (2009).

\section{OS PCN PARA O ENSINO DE MATEMÁTICA E OS PROJETOS POLITICOS PEDAGÓGICOS}

Os PCN são diretrizes elaboradas pelo Governo Federal, entre as quais estão as Diretrizes Curriculares da Matemática ${ }^{6}$ para a Educação Básica. Nessas normas consta que a Matemática, no Ensino Fundamental, deve valorizar as experiências do aluno e a disciplina como instrumento de compreensão e manuseio de atividades do dia-a-dia, entendendo que a matemática estimula o conhecimento, o interesse, a curiosidade, a investigação, a aprendizagem, a aquisição e o desenvolvimento de outros conhecimentos.

Analisar os PCN e os PPPs para entender a filosofia e os objetivos de ensino de uma escola, possibilita ver também o que cada escola propõe, como desenvolve seu currículo e ações para alcançar os objetivos que pretende. No contexto atual, muitas reformas curriculares estão sendo propostas para atender as rápidas mudanças do nosso tempo. Nesse sentido: "O papel fundamental da educação no desenvolvimento das pessoas e das sociedades amplia-se ainda mais no despertar do novo milênio e aponta para a necessidade de se construir uma escola voltada para a formação de cidadãos.” (BRASIL, 1998, p. 5). As mudanças no currículo também são "o resultado de lutas para produzir e institucionalizar determinadas identidades pedagógicas e, para tanto, são mobilizados recursos humanos, materiais e simbólicos de forma a alcançar tal objetivo.” (LOPES, 2002, p. 145-146).

Assim, as propostas do Ministério da Educação e das Secretarias de Educação trazem as normas e os objetivos do processo educacional. Os PCN visam auxiliar a escola e o professor no processo de pesquisa e elaboração de um projeto de estudo que atenda aos alunos de uma região, observando as especificidades de um grupo, dentro do contexto pedagógico da escola. O PPP tem a responsabilidade de definir e organizar atividades necessárias à formação

\footnotetext{
${ }^{6}$ Disponível em: <http://portal.mec.gov.br/seb/arquivos/pdf/matematica.pdf〉. Acesso em 18 fev. 2014.
} 
de cidadãos éticos e críticos, devendo estar de acordo com os PCN. Um PPP deve contemplar todas as metas que a escola deseja atingir, com propostas de ação concreta, pois serve de parâmetro para o planejamento dos professores. Sabe-se que a construção de um PPP requer constantes atualizações e que essas devem ser o mais abrangente possível, mas contemplar todas as especificidades, em um mesmo documento que oriente todas as práticas pedagógicas é um desafio. Os projetos de cada escola têm que deixar claro a filosofia da instituição e seus objetivos, mas também devem deixar espaços para flexibilizar o currículo de forma a atender as diversidades que surgirem. Assim, os PCN de Matemática atribuem a cada escola, a responsabilidade pelas questões específicas que atendem.

Os PCN propõem um debate educacional envolvendo escolas, governo e sociedade, para que se discuta o que é importante para os direitos dos sujeitos e o que deve reger cada escola de acordo à comunidade a que se destina. São documentos que servem para orientar e apoiar o desenvolvimento de projetos educativos das escolas em consonância com as mudanças que ocorrem na sociedade. Mas cabe a cada escola refletir sobre os conhecimentos específicos que considera necessário trabalhar com a comunidade escolar que atende, assim como os professores têm autonomia para desenvolver suas práticas pedagógicas, os planejamentos de aulas, a análise e a seleção de materiais didáticos e recursos tecnológicos que contemplem as metas que a escola quer atingir.

As diversidades culturais são marcas na formação de identidades, por isso, entender as diferenças que compõem a sociedade, trabalhar para que as diferenças sejam respeitadas faz parte da construção da cidadania. Os Projetos Político-Pedagógicos das escolas visam contemplar essas diferenças, para que todos façam parte de seus planejamentos, e, assim, se promova a inclusão e participação de todos, através de ações e práticas que atendam os objetivos traçados.

O currículo na educação de surdos começou a ser pensado muito recentemente e a cultura surda e a construção de identidades na escola são tópicos que ainda precisam ser mais investigados. Porém, vemos que a mobilização da comunidade surda, através de suas lutas por uma educação bilíngue de qualidade, tem provocado mudanças de ênfase nos espaços educacionais. Pelas lutas do movimento surdo, assim como pelas pesquisas e dados estatísticos que mostram o fracasso de propostas anteriores, as escolas vêm se mobilizando e discutindo sobre metodologias visuais, cultura surda e a importância da comunidade de pares para o desenvolvimento de identidades surdas como diferenças linguísticas, políticas e 
culturais. Elaborar currículos com propostas que possam provocar no aluno a curiosidade pelos fatos que estão ocorrendo no mundo, instiga o aluno surdo a ter um olhar crítico sobre acontecimentos que estão a sua volta, fazendo com que fique conectado com as coisas que acontecem ao seu redor, como menciona um dos objetivos do PCN, segundo o qual a escola e o currículo devem fazer com que:

[os alunos sejam capazes de] questionar a realidade, formulando-se problemas e tratando de resolvê-los e utilizando para isso o pensamento lógico, a criatividade, a intuição, a capacidade de análise crítica, selecionando procedimentos e verificando sua adequação. (BRASIL, 1998, p. 8).

O objetivo mencionado abrange o ensino da Matemática, a resolução de problemas e a meta de preparar alunos para o exercício de cidadania. Saber conviver e compartilhar prepara o educando para as relações na sociedade e, no caso do aluno surdo, a língua de sinais faz parte do processo de construção da sua identidade, pois é através dela que ele expressa seus pensamentos e emoções e pode se tornar um ser social e atuante.

Toda a educação tem como foco estimular o pensamento, construir uma linguagem que prepare o aluno para o exercício de direitos e deveres. No caso do ensino de Matemática para alunos surdos, esses objetivos devem ser trabalhados em língua de sinais, através da qual o aluno surdo poderá conhecer e entender os conteúdos, construindo valores e fortalecendo-se como sujeito. O raciocínio lógico e a construção de conhecimentos matemáticos desenvolvidos em atividades centradas na língua de sinais, abrem outras possibilidades de compreensão, podendo fazer com que a aprendizagem seja construída mais rapidamente e o aluno possa interagir com o conhecimento fazendo uso adequado do que aprendeu para planejar e organizar sua vida. $\mathrm{O}$ conhecimento matemático também se faz necessário para resolver questões do cotidiano: são os ajustes de horários na nossa agenda diária; são as contas a pagar; as compras necessárias à sobrevivência do dia-a-dia; os cálculos de consumo e gastos; o cálculo de tempo, assim como conhecimentos científicos e tecnológicos que exigem raciocínio lógico.

Segundo várias pesquisas - e nossas próprias experiências como professoras e pesquisadoras na área -, a variedade de atividades visuais e a língua de sinais na educação de surdos, podem contribuir para que o aluno construa novos conhecimentos, desenvolvendo também habilidades de estudo. Nas análises, discussões e proposições do planejamento pedagógico torna-se preponderante, assim, considerar as particularidades dos alunos, pois isso 
ALBERTON, B. F.; THOMA, A. S,

possibilita organizar e colocar em ação uma proposta pedagógica que se atenha às singularidades, voltando as práticas para a produção de outras formas de pensar o currículo e o planejamento.

Para que as mudanças aconteçam, as experiências e a reflexão sobre as práticas, assim como uma análise do contexto para propor as estratégias e os recursos adequados para o atendimento do aluno surdo, requer o conhecimento da cultura surda e o entendimento do que pode contribuir com o jeito surdo de aprender. $\mathrm{O}$ ensino de Matemática, ao trabalhar conceitos matemáticos (palavras e símbolos) em Libras e através de metodologias visuais, favorece a apreensão de conhecimentos. Compreendendo conceitos, os alunos produzem e desenvolvem o raciocínio lógico através da língua de sinais, levantando dúvidas, perguntas e buscando soluções.

O professor de Matemática, para atuar com alunos surdos, precisa de conhecimento sólido tanto da disciplina que vai ensinar como da língua e da cultura surda. A partir da língua de sinais, os conteúdos poderão ser ensinados, mostrando fatos e informações da atualidade, relacionando-os com temas da aula. Nessa interação entre as duas línguas, o aluno surdo, em geral, sente-se motivado a descobrir outros conhecimentos, interessando-se pelas questões que o cerca, o mundo, as pessoas, os acontecimentos. Como colocam os autores Borges e Nogueira (2013), o ensino de Matemática e os materiais manipuláveis são mecanismos facilitadores para a compreensão dos conteúdos.

Elaborar aulas com planejamentos que considerem a cultura da comunidade surda, com recursos e avaliações em língua de sinais, favorece a interação entre Matemática e a cultura, pois "quando o conhecimento matemático ensinado na escola estiver atrelado à cultura dos sujeitos surdos, outras formas de fazer e pensar matematicamente, advindas das demais culturas, serão possibilitadas.” (KIPPER; ALBERTON, 2014, p. 8).

Muitos professores, surdos ou ouvintes, com fluência em Libras, com conhecimento da cultura e identidades surdas, vêm priorizando recursos visuais. Conforme coloca o Relatório sobre a Política Linguística de Educação Bilíngue - Língua Brasileira de Sinais e Língua Portuguesa: "no contexto da educação bilíngue, professores criam seu próprio material didático bilíngue, a partir da inserção de ilustrações e da língua de sinais escrita, que permitem associação de desenhos com a língua, e, por conseguinte, que levam à aprendizagem de associações.” (BRASIL/MEC/SECADI, 2014, p. 14). Em uma proposta bilíngue de educação, os artefatos visuais levam a uma aprendizagem por associação, 
relacionando os elementos de duas línguas no processo de aquisição do conhecimento. As estratégias visuais enriquecem a aprendizagem, despertando a curiosidade do aluno: ao compreender uma informação, o aluno assimila, discute, faz perguntas e busca respostas, e, nesse processo, vai descobrindo novas fontes de informação. Através das práticas e experiências visuais, o aluno surdo vai interagindo com os fatos e informações, formulando suas próprias questões: "o que faz com que as experiências se estruturem de maneira diferente, ocasionando a construção do mundo das percepções, representações e imagens, sobre bases diferentes." (NOGUEIRA et al.,2013, p. 175).

O ensino de Matemática, ao incluir atividades visuais, com metodologias apropriadas para o ensino de surdos, oportuniza entendimento e criatividade para resolver problemas, conforme escrevem Viana e Barreto (2014, p. 47) que: "na educação é importante que o aluno com surdez tenha oportunidade de interagir no ambiente educacional com a utilização de imagens visuais em seus aspectos lúdicos”.

Os Parâmetros Curriculares Nacionais (PCN) e os Projetos Político-Pedagógicos (PPPs) das escolas pesquisadas ${ }^{7}$, todas localizadas na cidade de Porto Alegre, foram selecionados por trabalhar com a educação de surdos e a disciplina de Matemática centrada na Língua Brasileira de Sinais. Os PCN, para área de Matemática, abrem espaço para que os conteúdos sejam flexibilizados de acordo com as necessidades dos alunos.

A partir dessa flexibilidade de escolha, a construção de "agrupamentos temáticos" (ANDRADE, 2012) foi feita a partir da leitura e releitura dos materiais, com "pausas para planejar, anotar e avaliar os nossos movimentos; e para rever, ressignificar e olhar sob outros ângulos nossas perguntas e objetos.” (MEYER; PARAÍSO, 2012, p. 17). Nesse enfoque, foi feita a leitura dos documentos, estudados os projetos e, por fim, feito o agrupamento de enunciados que constituem discursos sobre Educação Matemática para surdos, para entendermos como vem sendo orientada e desenvolvida essa disciplina nas escolas e que sujeitos elas buscam constituir.

\footnotetext{
${ }^{7}$ Para a produção de dados, inicialmente foi feito contato com quatro escolas através de e-mail. Dessas, três escolas aceitaram participar da pesquisa. Ao visita-las, foi apresentado o Termo de Consentimento Livre e Esclarecido (TCLE) e explicado para as supervisões e direções das escolas os objetivos da pesquisa e as análises que a envolveriam, sendo garantido o sigilo ético das informações e dados produzidos. As escolas mostraram-se receptivas, entenderam a pesquisa e autorizaram a realização da mesma, cedendo seus PPPs para que fossem analisados.
} 
ALBERTON, B. F.; THOMA, A. S,

As escolas foram nomeadas pelos símbolos matemáticos $\alpha$ (alfa), $\beta$ (beta) e $\gamma$ (gama), observando a ordem em que foram respondendo a pesquisa. As três escolas trabalham com educação bilíngue e atendem, especificamente, alunos surdos. Observa-se que existe respeito e valorização das identidades e da cultura surda dentro dos espaços escolares visitados.

Para o entendimento dos Projetos Político-Pedagógicos de cada uma das escolas, foram analisados os documentos disponibilizados pela direção ou coordenação pedagógica. Os PPPs propõem o debate sobre a ação educacional, estabelecendo as diretrizes, organizando as propostas de ação e sistematizando as atividades desenvolvidas. Dessa forma, as reflexões e discussões em torno do PPP, produzem outras possibilidades de ensino-aprendizagem, onde as ações educativas passam a ser vistas com um olhar mais cuidadoso, para que o aluno possa transformar-se em sujeito do seu próprio conhecimento.

\section{MATEMÁTICA PARA A CIDADANIA: a escola deve trabalhar "conhecimentos socialmente elaborados e reconhecidos como necessários ao exercício da cidadania"}

Nos documentos analisados é recorrente o discurso de que os alunos devem construir o conhecimento matemático a partir de valores e questões sociais que o preparem para o exercício da cidadania. Compreender que a Matemática está presente na vida cotidiana de todos os cidadãos e que esse saber capacita o indivíduo para exercer direitos e deveres, em todas as esferas da sociedade, desmistifica a ideia de que a Matemática é um "bicho papão". Saber resolver problemas, fazer cálculos e proporções habilita a pessoa para o mundo do trabalho e também para o gerenciamento de sua própria vida.

Os PCN orientam as escolas a proporcionarem aos alunos contato com o conjunto de conhecimentos socialmente elaborados e reconhecidos para um efetivo exercício da cidadania (BRASIL, 1998, p.5), com responsabilidade e autonomia. Assim, se pretende que todos os alunos tenham acesso a um conjunto de conhecimentos elaborados e reconhecidos como importantes para o exercício de cidadania, sendo considerado cidadão aquele que "goza dos direitos civis e políticos de um Estado ou país" (HOUAISS; SALLES, 2004, p. 157).

O currículo da Matemática também deve propor situações e atividades que produzam soluções para problemas da vida cotidiana, despertar e estimular o aluno a resolver questões rotineiras, fazê-lo perceber que números e cálculos são instrumentos de sobrevivência 
humana, são questões presentes nessa área do conhecimento. Nesse sentido, os objetivos dos PCN, para o ensino fundamental, pregam que os alunos sejam capazes de:

- compreender a cidadania como participação social e política, assim como exercício de direitos e deveres políticos, civis e sociais, adotando, no dia-a-dia, atitudes de solidariedade, cooperação e repúdio às injustiças, respeitando o outro e exigindo para si o mesmo respeito; [...]- desenvolver o conhecimento ajustado de si mesmo e o sentimento de confiança em suas capacidades afetiva, física, cognitiva, ética, estética, de inter-relação pessoal e de inserção social, para agir com perseverança na busca de conhecimento e no exercício da cidadania. (BRASIL, 1998, p. 7).

Para alcançar tais objetivos, os alunos precisam de atividades que os preparem para o exercício da cidadania através da participação social e política, com atitudes de respeito e cooperação. Os PCN colocam também que "compreender a cidadania é conhecer direitos e deveres, é conhecer a si mesmo, sendo capaz de reconhecer suas capacidades, construindo e desenvolvendo seus deveres civis e sociais" (idem). No caso de pessoas surdas, conhecer seus direitos linguísticos e culturais é o primeiro exercício para a cidadania, pois a partir deste conhecimento, os alunos poderão buscar outras formas de reivindicar seus direitos, com ética e justiça.

Planejar e organizar atividades, respeitando compromissos, produz efeitos satisfatórios nas relações sociais, pois a partir de estruturas bem planejadas, o aluno consegue cumprir suas tarefas. Ao distribuir adequadamente o seu tempo e os seus compromissos, o aluno emprega os conhecimentos matemáticos, sendo capaz de ações solidárias e éticas, entendendo que os direitos terminam onde começa o direito do outro. A participação social e política devem estar inseridas nos PPPs das escolas, levando o aluno a aprender que o respeito, a justiça e a ética fazem parte das relações sociais mais amplas.

A linguagem matemática faz parte do nosso dia-a-dia. A todo o momento, somos solicitados a tomar decisões que precisam ser resolvidas a partir de cálculos: uma distância a ser percorrida, o tempo gasto em determinado percurso, o valor de determinado produto, enfim, não podemos viver sem os números e os cálculos. Hoje, é quase impossível navegar na internet, assistir televisão, ler o jornal ou a revista, fazer compras, sem precisar dos conhecimentos matemáticos. O conhecimento da linguagem matemática, dos conceitos de cálculos, de porcentagens, gráficos e tabelas, faz parte da habilidade de analisar dados e melhora as competências e habilidades no cumprimento de tarefas e compromissos. 
Em um contexto de justiça e solidariedade, a Matemática promove uma reflexão sobre as injustiças sociais, analisando dados, descrevendo fatos do mundo, apresentando percentuais de problemas sociais, desenvolvendo um pensamento lógico que analisa fatos com base em números. Através da Matemática podemos conhecer aspectos da vida de um povo, como os índices da saúde, os percentuais de desemprego, o custo de vida, elementos que são apresentados todos os dias na mídia, mas que, muitas vezes, não são bem entendidos por aqueles que não aprenderam o significado desses números. Esses índices podem produzir atitudes e ações, mas às vezes passam despercebidos para algumas pessoas que não têm conhecimento para refletir sobre os impactos de preços e valores no custo de vida, na defasagem de salários, na melhoria de ganhos, nas horas de trabalho, por exemplo. O saber matemático ajuda a pessoa a planejar suas ações, tomando decisões oportunas para a vida, sendo capaz de aceitar ou criticar questões sociais, políticas e econômicas. Um cidadão precisa conhecer direitos, cumprir deveres, pagar impostos, honrar compromissos, planejar compras, respeitar leis, votar com consciência, obedecer ao trânsito, agir com igualdade, justiça, respeito e ética.

Os PPPs das escolas analisadas apresentam objetivos que produzem planejamentos de acordo com as necessidades visuais do aluno surdo. Os conteúdos trabalhados em língua de sinais e de recursos visuais motivam o aluno para a construção de conhecimentos, a partir dos estímulos oferecidos dentro de cada disciplina.

Ao analisarmos a Matemática como processo para a construção da cidadania, buscamos no currículo, menções de planejamento e organização de atividades que desenvolvam relações de respeito pelo outro, pela sociedade e pelo meio-ambiente. Ver na educação um fator de promoção para a cidadania do aluno surdo exige do professor conhecimento da identidade, da cultura e dos costumes da comunidade surda, para fazer escolhas de conteúdos que sejam relevantes para ele e a sua comunidade.

Aprendendo em situações reais para lidar com um ambiente onde conhecimentos e informações resultem em soluções práticas, relacionando-as com o cotidiano, faz parte das metas estabelecidas pelos PCN, conforme os excertos abaixo:

[a escola] tem como princípio norteador estimular o educando para o exercício da cidadania, tendo como visão de cidadão o sujeito participativo, democrático, crítico, consciente dos seus direitos e deveres, protagonista da sua história e atuante na construção de uma sociedade justa e igualitária. (PPP, ESCOLA $\alpha$, p. 13). 
[a escola tem por objetivo de] propiciar um espaço coletivo de construção de sujeitos críticos e agentes transformadores da sociedade, visando o exercício da cidadania. (PPP, ESCOLA $\alpha$, p. 18).

No ensino de alunos surdos, as práticas produzidas em ambientes reais são contribuições que resultam em um conhecimento concreto, alicerçado na experiência. Nas análises dos PPPs das escolas para surdos, o ensino de Matemática consegue articular conhecimento e motivação, com recursos visuais, coloridos e atraentes. Assim, como protagonista, o aluno sente-se desafiado a buscar outras descobertas.

A escola $\alpha$ apresenta no PPP, a proposta de uma educação voltada para a construção de sujeitos que sejam conscientes dos seus deveres e atuantes na sociedade, buscando ações que promovam oportunidades de interação com o outro, para que exercitem a democracia como forma de respeito e justiça.

\footnotetext{
As concepções aqui explicitadas são pautadas no respeito à diversidade, nos espaços e seus tempos diferenciados, buscando cidadania, por meio da inclusão e justiça social. Segundo o Estatuto da Criança e do Adolescente, a criança e o adolescente têm direito à educação, visando ao pleno desenvolvimento de sua pessoa, preparo para o exercício da cidadania (...). (REGIMENTO, ESCOLA $\gamma$, p. 5).
}

[a escola como um espaço vivo e democrático privilegiado da ação educativa] que tenha espaços de formação para os educadores, na perspectiva da construção de sujeitos críticos e de investigação permanente da realidade social, tendo como objetivo a qualificação da ação pedagógica e o exercício de sua cidadania. (REGIMENTO, ESCOLA $\gamma$, p. 5-6).

Ao analisar os documentos da escola $\gamma$, encontramos a qualificação da ação pedagógica como proposta para criar sujeitos críticos e capazes. Saber aceitar, acolher e respeitar as diferenças contribui para a formação de um cidadão participativo e justo. Através de atividades de respeito e acolhimento, a escola busca formar pessoas que possam agir com ética e justiça frente às diversas situações sociais. Todos os PPPs das escolas analisadas consideram o que os PCN orientam, introduzindo em seus objetivos a busca pela formação de cidadãos críticos e capazes. Assim, a Matemática articula a vida com as ações da sociedade, para fortalecer a consciência de justiça e solidariedade.

Para as pessoas surdas, perceber-se cidadão é poder participar da sociedade, contribuindo com ideias e planejamento de atos civis e políticos. É poder dizer o que essa comunidade anseia e busca, exigindo uma educação de qualidade, na língua de sinais. Contar 
com intérpretes de Libras em todas as instâncias sociais também é uma necessidade das pessoas surdas. Algumas vezes, as dificuldades da comunidade surda em cumprir compromissos é, gerada pela falta de intérpretes de Libras ou pela impossibilidade de ter alguém com fluência em Libras para fazer a mediação entre o surdo e os espaços públicos por onde precisa transitar.

A escola precisa elaborar propostas que articulem conceitos matemáticos e a realidade, pois estes conhecimentos passam por todas as instâncias da vida, relacionando as ações do cotidiano com a construção da cidadania, do respeito de si e do outro, em todos os espaços de convivência.

Falar em formação básica para a cidadania significa refletir sobre as condições humanas de sobrevivência, sobre a inserção das pessoas no mundo do trabalho, das relações sociais e da cultura e sobre o desenvolvimento da crítica e do posicionamento diante das questões sociais. Assim, é importante refletir a respeito da colaboração que a Matemática tem a oferecer com vistas à formação da cidadania. (BRASIL, 1998, p. 26).

A expressão Formação de cidadania nos documentos analisados leva-nos a pensar de que forma o currículo de Matemática contribui para essa formação. Refletir sobre as condições humanas de sobrevivência e a inserção das pessoas no mercado de trabalho nos remete à formação de cidadãos. Os objetivos propostos no PCN nos dizem que a Matemática deve oferecer aos alunos, atividades que os levem a um posicionamento crítico frente às questões sociais. Argumentar e ter opinião própria habilita os sujeitos para que tenham autonomia e segurança no trato dos problemas. Entendemos que a precisão com os números e cálculos também podem contribuir para que o aluno avalie comportamentos mencionando-os como corretos ou inadequados. Assim, os números podem capacitar indivíduos para fazer julgamentos mais justos ao avaliar as relações que interferem e produzem condutas.

Nos documentos dos PCN, o papel da escola deve ser de provocar mudanças nos comportamentos, para que os alunos sejam desafiados a pensar, criar e buscar soluções. Os PPPs analisados, mostram que ações são propostas de forma a estimular alunos a compreender a importância da cidadania, aplicando os conhecimentos matemáticos em situações da vida cotidiana e atividades do mundo do trabalho, como vemos a seguir:

é papel da escola desenvolver uma educação que não dissocie escola e sociedade, conhecimento e trabalho e que coloque o aluno ante desafios que lhe permitam desenvolver atitudes de responsabilidade, compromisso, crítica, satisfação e 
reconhecimento de seus direitos e deveres. Nesse aspecto, a Matemática pode dar sua contribuição à formação do cidadão ao desenvolver metodologias que enfatizem a construção de estratégias, a comprovação e justificativa de resultados, a criatividade, a iniciativa pessoal, o trabalho coletivo e a autonomia advinda da confiança na própria capacidade para enfrentar desafios. [...] Para que ocorram as inserções dos cidadãos no mundo do trabalho, no mundo das relações sociais e no mundo da cultura e para que desenvolvam a crítica diante das questões sociais, é importante que a Matemática desempenhe, no currículo, equilibrada e indissociavelmente, seu papel na formação de capacidades intelectuais, na estruturação do pensamento, na agilização do raciocínio do aluno, na sua aplicação a problemas, situações da vida cotidiana e atividades do mundo do trabalho e no apoio à construção de conhecimentos em outras áreas curriculares. (BRASIL, 1998, p. 27 28).

Para que a Matemática desempenhe, no currículo, o seu papel na formação de capacidades intelectuais precisa focar em ações que estruturem o pensamento e o raciocínio, para que, a partir dessas ações, a construção do conhecimento seja ampliada para outras áreas curriculares. Criar atividades que envolvam grupos, em uma ação coletiva, desenvolve habilidades para saber dialogar, repartir tarefas, ter iniciativa, fazer interpretações de resultados com autonomia.

Também encontramos referências, nos PPPs, sobre a formação de cidadãos, o seguinte:

Educar e formar revela o desejo de transpor o processo educativo, e buscar também o formativo, ou seja, a construção de futuros cidadãos conscientes em seus direitos e deveres, dotados de sólidos valores morais e princípios éticos. (PPP, ESCOLA $\alpha, \mathrm{p}$. 12).

favorecer uma ação educativa integral, [...], que viabilize a participação do educando na construção da cidadania e da sua atuação como agente de transformação social, através do desenvolvimento da consciência crítica, do bom uso da liberdade e do senso de justiça; [...] atender às necessidades educacionais dos surdos, respeitando sua cultura, de modo a favorecer o resgate da cidadania; a promoção de suas potencialidades; o despertar para o compromisso comunitário e a vivência solidária participativa. (PPP, ESCOLA $\beta$, p. 18-19).

Para promover a cidadania, a escola propõe uma ação educativa integral, com a inserção de valores éticos e morais nos comportamentos, através de atividades individuais e coletivas, que desafiam o aluno a trabalhar o respeito, a justiça e a ética. Ao sentir-se valorizado, o aluno constrói o respeito por si mesmo e pelo outro. Assim, a exatidão na resolução de problemas pode levar a desenvolver discernimento para avaliar atitudes e condutas, formando sujeitos críticos, justos e responsáveis. 
Para dimensionar a Matemática no currículo do ensino fundamental é importante que se discuta sobre a natureza desse conhecimento e que se identifiquem suas características principais e seus métodos particulares como base para a reflexão sobre o papel que essa área desempenha no currículo, a fim de contribuir para a formação da cidadania. (BRASIL, 1998, p. 24).

VISÃO DE FUTURO: Sermos reconhecidos como uma escola dinâmica, integrada e comprometida com a educação de surdos e com a formação de cidadãos plenos, críticos, éticos e conscientes, cumprindo a responsabilidade social e respeitando as diferenças.[...] MISSÃO: Educar e formar cidadãos surdos qualificados e críticos, com base em princípios éticos para atuar como agentes transformadores frente às diferenças que permeiam a sociedade. (PPP, ESCOLA $\alpha$, p. 14-15).

O Currículo propõe flexibilidade e descentralização, reforçando a necessidade de construção de uma identidade coletiva em que as decisões e responsabilidades sejam compartilhadas em todos os níveis e modalidades de ensino, tendo como base o respeito aos direitos e deveres dos educandos, bem como aos/às professores/as e a comunidade escolar. No desenvolvimento do currículo a formação básica do cidadão, objetivo do ensino fundamental, deve estar articulada às áreas do conhecimento e as dimensões da vida cidadã, através dos temas transversais. (PPP, ESCOLA $\beta$, novo projeto).

O ensino da matemática deve estar voltado para a formação do cidadão, com o objetivo de favorecer conhecimentos específicos, deste componente curricular, que auxiliem na vivência, desta cidadania, dentro das relações sociais, culturais e de trabalho. Desta forma o aluno deve estar preparado para acompanhar uma pesquisa eleitoral, calcular o seu salário, utilizar um computador ou máquinas de calcular e até mesmo fazer suas próprias compras (dia-a-dia), aplicando conceitos numéricos, efetuando operações, calculando medidas e utilizando o raciocínio lógico nas diferentes situações. (PLANO DE ESTUDOS, Escola $\beta$ ).

Em todos os PCN e PPPs analisados, encontramos a recorrência de termos como construção de cidadania, exercício de cidadania e formação de cidadania, conforme os excertos apresentados acima. Na educação do aluno surdo constata-se que o conhecimento matemático leva à reflexão da realidade, de fatos, de experiências, de atitudes, normas e valores, e, a partir disso também são produzidos discursos que representam a luta política da comunidade surda, de acordo com a realidade social. Assim, cabe a cada escola estabelecer debates para que o professor planeje de acordo com o seu projeto pedagógico, promovendo ações voltadas à construção de seres justos, capazes e éticos.

A Língua Brasileira de Sinais é a representação máxima dos movimentos e lutas dos surdos, e, dentro dos documentos analisados, todas as escolas colocam o ensino da língua como o principal exercício de cidadania para o aluno surdo. $\mathrm{O}$ direito à educação na língua de sinais tem feito com que a comunidade surda seja atuante nas decisões que envolvem a educação de surdos: 


\begin{abstract}
A comunidade surda apresenta-se completamente presente dentro deste processo, que emerge com força total, com um novo e borbulhante discurso, que traz como "carro chefe" a Língua de Sinais a qual se tornou uma representação da luta política por identidade e direitos de cidadania, num espaço de discussão sobre alteridade e diferença, ganhando assim, espaço de "escuta" como sujeitos centrais dessa discussão que, ao mesmo tempo em que sugere inovações vai se confrontar com o discurso tradicional. [...] As escolas de surdos são espaços demarcados de construção da sua identidade, do contato com sua língua de uso, conhecimento da sua cultura, tornando-se um lugar de conquista e luta por seus direitos e sua cidadania. É apenas dentro deste ambiente favorável que se pode oferecer uma educação voltada para princípios culturais e humanísticos, promovendo o desenvolvimento de indivíduos cidadãos. (PPP, ESCOLA $\boldsymbol{\alpha}$, p. 8-9).
\end{abstract}

A escola $\alpha$ defende no PPP que a comunidade escolar surda deve fazer uso da língua de sinais, valorizando as identidades e a cultura surda. Isso representa a luta política por mais visibilidade social. A importância dos movimentos por uma educação de qualidade para os surdos ganhou força. As lutas pela transformação social da comunidade surda são formas de constituir a cidadania do aluno surdo. Os conhecimentos matemáticos voltaram-se para a necessidade de promover a construção da cidadania: melhorar condições de vida, favorecer projetos e sonhos - sonhos que habilitem para um trabalho digno, que ajudem a inibir atos de violência, diminuía os índices de desemprego, entre outros - e construir um mundo onde o lazer, a saúde, o trabalho façam parte da vida das pessoas. Onde o conhecimento matemático seja valorizado em um processo para crescimento e prestígio, com ações que façam parte dos objetivos educacionais em prol da cidadania.

A comunidade surda entende que o movimento de luta pelo reconhecimento da Libras, a valorização da cultura surda e as políticas linguísticas foram conquistas significativas para sobrevivência do surdo. Porém, Thoma e Klein (2010, p. 127) fazem algumas problematizações sobre isso:

Com o crescente desenvolvimento de pesquisas educacionais e interesse nos debates sobre educação, diferença e identidades, questionamos os efeitos de tais descrições dos sujeitos surdos. Concordamos que se faz necessário descrever, para fins de implementação de uma política de educação de surdos, quem são esses sujeitos $e$ como eles se comunicam, mas corremos o risco de, ao reduzirmos as descrições ao fator língua, manter binarismos e reforçar processos de in/exclusão, tanto entre surdos e ouvintes quanto entre os próprios surdos. Nesse sentido, somos provocadas a problematizar as possibilidades de sentidos que se produzem ao definirmos a educação bilíngue como a proposta desejável para os surdos. Até que ponto as mobilizações historicamente construídas pelos movimentos surdos, pautadas em referências culturalistas, remetem mais fortemente a discussões multi/interculturais do que a definição das línguas (Libras - Português) nos espaços escolares? 
ALBERTON, B. F.; THOMA, A. S,

E acrescentamos: Quais as perspectivas que a política linguística traz para construção da cidadania dos alunos surdos? As discussões sobre a educação bilíngue e política linguística, no ambiente escolar, sugerem que ações sejam construídas e implantadas dentro das salas de aula, para que os alunos possam interagir entre si e com o ambiente lá fora. Promover uma educação que traga a realidade para dentro da escola, com fatos e informações do cotidiano, a partir da língua de sinais, para que todos possam se apropriar do conhecimento e dos fatos, são desafios constantes do professor de surdos.

A partir de análises dos PCN e dos PPPs, buscamos os Planos de Estudos e neles também é recorrente o discurso de que a escola deve trabalhar "conhecimentos socialmente elaborados e reconhecidos como necessários ao exercício da cidadania”, para desenvolver a autonomia, crítica, senso de justiça e participação. A escola, ao refletir sobre o movimento e a política surda, associa conhecimento e realidade, fortalecendo a comunidade e as identidades surdas. As discussões sobre a cultura surda valorizam os sujeitos que são constituídos nessa realidade.

\section{CONSIDERAÇÕES FINAIS}

A análise do PCN para o Ensino de Matemática e dos Projetos Político-Pedagógicos (PPPs) das escolas mostrou que documentos têm como objetivo promover o debate entre as práticas e experiências pedagógicas, antes de estabelecer propostas de diretrizes e ações, organizando as atividades e os projetos que deverão ser desenvolvidos por cada escola, em cada nível da educação.

A matemática para a cidadania aparece como uma questão fundamental, recorrente nos excertos dos materiais apresentados neste artigo. Nos PCN, PPPs e Planos de Estudos é bastante presente o discurso de que sujeito surdo precisa construir conhecimentos matemáticos para se constituir cidadão participativo, crítico, justo e autônomo.

A análise dos Projetos Político-Pedagógicos (PPPs) das escolas mostra a promoção de debates sobre práticas e experiências pedagógicas, antes de estabelecer propostas de diretrizes e ações. As atividades e os projetos que deverão ser desenvolvidos por cada etapa são planejados e organizados no início de cada ano letivo. Analisando os documentos das escolas $\alpha, \beta$ e $\gamma$, constatamos que as três escolas vêm fazendo seus estudos considerando as lutas políticas que nasceram dos movimentos surdos. Estas escolas também buscam preservar e 
promover os espaços da cultura surda, onde é reconhecida a diversidade cultural da comunidade surda.

Assim, entende-se que cultura e identidade surdas são questões presentes na educação matemática para surdos, tanto pelo reconhecimento, uso e valorização da Língua Brasileira de Sinais como primeira língua dos surdos, como através de práticas visuais para que o aluno surdo construa os conhecimentos matemáticos.

\title{
MATHEMATICS FOR CITIZENSHIP: CURRICULUM DISCOURSES ABOUT MATHEMATICS EDUCATION FOR THE DEAF
}

\begin{abstract}
This paper analyzes discourses about Mathematics Education and the way that they have constituted the practices developed with deaf students. As our analysis material, we considered both the National Curriculum Guidelines of the area of Mathematics for Elementary Education and the Political-Pedagogical Projects of three schools for the deaf. The analyses were grounded the notion of discourse developed by Michel Foucault (1996). We also established a dialogue with Viana \& Barreto (2014) and Borges \& Nogueira (2013) to think about Mathematics Education, and Hall (2000), Thoma \& Klein (2010) and Thoma (2012) to discuss about identities, deaf difference, curriculum, culture and power. The discourse evidencing that the deaf subject should construct mathematical knowledges to become a participatory, critic, fair and autonomous citizen is often seen in the analyzed Guidelines and Projects. Therefore, our focus here is on the discourses about Mathematics for Citizenship.
\end{abstract}

Keywords: Cultural Studies; Mathematics Education for the Deaf; Brazilian Sign Language; Deaf Identities; Discourse

\section{MATEMÁTICA PARA CIUDADANOS: DISCURSOS CURRICULARES SOBRE LA ENSEÑNANZA DE MATEMATICA PARA SORDOS}

\section{Resumen}


ALBERTON, B. F.; THOMA, A. S,

En este artículo analizamos los discursos sobre la enseñanza de matemática y como éstos constituyen las prácticas desenvueltas con alumnos sordos. Como material de análisis consideramos los Parámetros Curriculares Nacionales (PCN) del área de matemáticas para la Enseñanza Fundamental y los Proyectos Políticos- Pedagógicos (PPPs) de tres escuelas para sordos. Los análisis son realizados a partir de la noción del discurso desarrollado por Michael Foucault (1996). También dialogamos con Viana y Barreto (2014) y Borges y Nogueira (2013) para razonar sobre la enseñanza de matemática así como con Hall (2000), Thoma y Klein (2010) y Thoma (2012) para discutir sobre identidades, diferencia sorda, currículo, cultura y poder. En los PCN y PPPs analizados, está bastante presente el discurso de que una persona sorda necesita construir conocimientos matemáticos para formarse como ciudadano participativo, crítico, justo y autónomo. Así, nuestro recorte aquí, son los discursos sobre matemática para los ciudadanos.

Palabras clave: Estudios Culturales; Educación Matemática para Sordos; Lengua Brasileña de Señales; Identidades Sordas; Discurso

\section{REFERÊNCIAS}

ANDRADE, Sandra dos Santos. A Entrevista Narrativa Ressignificada nas Pesquisas Educacionais Pós-estruturalistas. In: MEYER, Dagmar Estermann; PARAÍSO, Marlucy Alvez. (Orgs.). Metodologias de Pesquisas Pós-estruturalistas em Educação. Belo Horizonte: Mazza Edições, 2012.

ARNOLDO JR., Henrique; RAMOS, Maurivan G.; THOMA, Adriana da Silva. O uso do Multiplano por alunos surdos e o desenvolvimento do pensamento geométrico. In: Caderno CEDES. Campinas, v. 33, n. 91, p. 387-409, set.-dez., 2013. http://dx.doi.org/10.1590/S010132622013000300006 Acesso em: 6 Jan. 2014.

BORGES, F.A.; NOGUEIRA, C.M.I.. Uma Panorama da inclusão de Estudantes Surdos nas aulas de Matemática. In: NOGUEIRA, Clélia Maria Ignatius (Org.). Surdez, inclusão e matemática. Curitiba: Editora CRV, 2013, p. 43-70.

BRASIL. Secretaria de Educação Fundamental. Parâmetros Curriculares Nacionais: Terceiro e quarto ciclos do ensino fundamental: Matemática. Brasília: MEC/SEF. 1998. Disponível em: <http://portal.mec.gov.br/seb/arquivos/pdf/matematica.pdf> Acesso em 18 Fev. 2014.

BRASIL/MEC/SECADI. Relatório do Grupo de Trabalho designado pelas Portarias $n^{o}$ 1.060/2013 e $n^{\circ}$ 91/2013: subsídios para a Política Linguística de Educação Bilíngue - Língua Brasileira de Sinais e Língua Portuguesa - a ser implementada no Brasil. Disponível em: 
<http://www.bibliotecadigital.unicamp.br/document/?code=56513>. Acesso em: 28 Abr. 2014.

CAPOVILLA, Fernando. Entrevista Prof à Globo News: Libras e educação bilíngue de surdos. Disponível em: https://www.youtube.com/watch?v=uVbzA7fpJWE\&noredirect=1

CARNEIRO, Kátia Tatiana Alves. Cultura Surda na aprendizagem matemática da sala de recurso do Instituto Felipe Smaldone: uma abordagem Etnomatemática. In: $4^{\circ}$ Congresso Brasileiro de Etnomatemática, 2012, Belém. Anais do $4^{o}$ Congresso Brasileiro de Etnomatemática, 2012, Belém. Disponível em: <http://www.cbem4.ufpa.br/anais/Arquivos/CC_CARNEIRO.pdf>. Acesso em: 24 Out. 2014.

CIDADANIA. In: Dicionário Houaiss da Língua Portuguesa. Rio de Janeiro: Objetiva, 2004.

CIDADÃO. In: Dicionário Houaiss da Língua Portuguesa. Rio de Janeiro: Objetiva, 2004.

FOUCAULT, Michel. A ordem do discurso. 3. ed. São Paulo: Editora Loyola, 1996. p. 5-20.

HALL, Stuart. Quem precisa da identidade? In: SILVA, Tomaz Tadeu (Org. e Trad.). Identidade e Diferença: A perspectiva dos Estudos Culturais. Petrópolis, Rio de Janeiro: Editora Vozes, 2000, p. 103-131.

KIPPER, D.; ALBERTON, B.F.A..Currículo de Matemática: Estratégias e recursos de ensino para alunos surdos. In: X Anped Sul, 2014, Florianópolis - SC. Anais da X Anped Sul. Florianópolis - SC. 2014. Disponível em: <http://xanpedsul.faed.udesc.br/arq_pdf/7880.pdf>. Acesso em: 24 Out. 2014.

LOPES, Alice Casimiro. Parâmetros curriculares para o Ensino Médio: quando a integração perde seu potencial crítico. In: LOPES, Alice Casimiro; MACEDO, Elizabeth (Orgs.). Disciplinas e integração curricular: história e políticas. Rio de Janeiro: DP\&A, 2002, p. 145176.

MEYER, D.E.; PARAÍSO, M.A.. Metodologias de pesquisas pós-críticas ou Sobre como fazemos nossas investigações. In: (Orgs.). Metodologias de pesquisas pós-críticas em educação. Belo Horizonte: Mazza Edições, 2012, p. 15-22.

MORAIS, Mônica Zavacki de; LUNARDI-LAZZARIN, Márcia Lisa. Pedagogia e Diferença: capturas e resistências nis discursos curriculares da educação de surdos. In: THOMA, Adriana da Silva; KLEIN, Madalena (Orgs.). Currículo e avaliação: a diferença surda na escola. Santa Cruz do Sul: EDUNISC, 2009, p. 16-31.

NOGUEIRA, Clélia Maria et al. Os surdos e a Inclusão: uma análise pela via do ensino de Matemática nos Anos Iniciais do Ensino Fundamental. In: NOGUEIRA, Clélia Maria Ignatius (Org.). Surdez, inclusão e matemática. Curitiba: Editora CRV, 2013, p. 163-184. 
ALBERTON, B. F.; THOMA, A. S,

SKLIAR, Carlos. Um olhar sobre o nosso olhar acerca da surdez e das diferenças. In:

(Org.). A surdez: um olhar sobre as diferenças. 6. ed. Porto Alegre: Editora Mediação, 2013, p. 7-32.

THOMA, Adriana da Silva. A afirmação da diferença e da cultura surda no cenário da educação inclusiva: desafios para o currículo. In: SARAIVA, Karla; MARCELLO, Fabiana de Amorim. (Orgs.). Estudos Culturais e Educação: desafios atuais. 1. ed. Canoas: Editora da ULBRA, 2012, p. 205-215.

THOMA, A.S.; KLEIN, M. Experiências educacionais, movimentos e lutas surdas como condições de possibilidade para uma educação de surdos no Brasil. In: Cadernos de Educação/Faculdade de Educação- UFPeL - ano 19, n. 36, mai.-ago., 2010. Ed. UFPEL. Pelotas, RS. p. 107 - 131. Disponível em:

<http://periodicos.ufpel.edu.br/ojs2/index.php/caduc/article/viewFile/1603/1486>. Acesso em: 1 Dez. 2014.

VEIGA-NETO, Alfredo. Foucault \& a Educação. 3. ed. Belo Horizonte: Autêntica Editora, 2011.

VIANA, F.R.; BARRETO, M.C. O Ensino de Matemática para alunos com Surdez: Desafios Docentes, Aprendizagens Discentes. Curitiba: Editora CRV, 2014.

Data de recebimento: 30/07/2015

Data de aceite: $27 / 10 / 2015$ 